\title{
High temperature and high pressure rheological properties of high-density water-based drilling fluids for deep wells
}

\author{
Wang Fuhua ${ }^{1 *}$, Tan Xuechao ${ }^{1}$, Wang Ruihe1, Sun Mingbo ${ }^{1}$, Wang $\mathbf{L i}^{2}$ and \\ Liu Jianghua ${ }^{3}$
}

${ }^{1}$ College of Petroleum Engineering, China University of Petroleum, Qingdao, Shandong 266555, China

${ }^{2}$ Institute of Oil Production Engineering, Daqing Oil Company, Daqing, Heilongjiang 163453, China

${ }^{3}$ Institute of Oil Production Technology, Xinjiang Oil Company, Kelamayi, Xinjiang 834000, China

(C) China University of Petroleum (Beijing) and Springer-Verlag Berlin Heidelberg 2012

\begin{abstract}
To maintain tight control over rheological properties of high-density water-based drilling fluids, it is essential to understand the factors influencing the rheology of water-based drilling fluids. This paper examines temperature effects on the rheological properties of two types of high-density water-based drilling fluids (fresh water-based and brine-based) under high temperature and high pressure (HTHP) with a Fann 50SL rheometer. On the basis of the water-based drilling fluid systems formulated in laboratory, this paper mainly describes the influences of different types and concentration of clay, the content of a colloid stabilizer named GHJ-1 and fluid density on the rheological parameters such as viscosity and shear stress. In addition, the effects of aging temperature and aging time of the drilling fluid on these parameters were also examined. Clay content and proportions for different densities of brine-based fluids were recommended to effectively regulate the rheological properties. Four rheological models, the Bingham, power law, Casson and H-B models, were employed to fit the rheological parameters. It turns out that the $\mathrm{H}-\mathrm{B}$ model was the best one to describe the rheological properties of the high-density drilling fluid under HTHP conditions and power law model produced the worst fit. In addition, a new mathematical model that describes the apparent viscosity as a function of temperature and pressure was established and has been applied on site.
\end{abstract}

Key words: High-density water-based drilling fluid, rheological behavior, clay, high temperature high pressure, linear fitting, rheological model, mathematical model

\section{Introduction}

One of the greatest problems encountered in deep well drilling is that drilling fluid requires excellent thermal stability and high density due to the high temperature and high pressure (HTHP) reservoir conditions. Environmental considerations and cost concerns have stimulated new interest in the use of water-based drilling fluid in deep wells where oil-based drilling fluid has previously been preferred. Therefore, an improved water-based drilling fluid system is needed to meet these reservoir conditions, and the key to designing this system is to control the rheological properties of the drilling fluid (Pu et al, 2001; Wang and Wu, 2004; Wang et al, 2007). To provide better control of rheological properties and excellent thermal stability, the activated weighting agents, thermally stable clay and various fluid systems with temperature and contaminant tolerance have also been commercialized. More and more filtration control polymers, which provide suitable filtration and rheological properties and high thermal stability, have appeared on the market. In addition, the micro-mechanisms of rheology at high temperatures are being identified (Ezell and Harrison, 2008; Attia et al, 2010; Samaei and Tahmasbi, 2007; Tehrani et al, 2007; Kar et al, 2009). High-density water-based drilling fluid behaves as a viscous colloidal suspension system, possessing a high solid phase content, high dispersion of solids and a low free water content. Invading cuttings are difficult to remove from the contaminated fluid. Severe down-hole conditions also pose a challenge to the control over fluid rheological properties. So research on the HTHP rheological properties of high-density water-based fluid has been conducted to help bridge the gap in deep well drilling fluid and deep formation exploration. 


\section{Rheological properties of water-based drilling fluids}

\subsection{Formulations of water-based drilling fluids}

Fresh water and brine were used to prepare drilling fluids and the formulations were optimized on the basis of laboratory experiments. The additives used in water-based drilling fluids are listed in Table 1.

Table 1 Drilling fluid compositions

\begin{tabular}{|c|c|c|c|c|}
\hline Component & Function & $\begin{array}{l}\text { Chemical } \\
\text { composition }\end{array}$ & $\begin{array}{l}\text { Fresh water-based } \\
\text { drilling fluid }\end{array}$ & Brine-based drilling fluid \\
\hline Water, $\mathrm{mL}$ & - & - & 100 & 100 \\
\hline Sodium bentonite, $\mathrm{g}$ & Rheology control & - & 1.0 & 1.0 \\
\hline Sepiolite, $g$ & Rheology control & - & 1.0 & 1.0 \\
\hline $\mathrm{NaCl}, \mathrm{g}$ & - & - & 0 & 15 \\
\hline GHJ-1, g & Colloid stabilizer & Copolymer of propylene monomers & 1.5 & 1.5 \\
\hline JZA-1, g & Filtration control & Modified lignite & 4.0 & 4.0 \\
\hline GJZA-1, g & Filtration control & Modified sulfonated phenolic resins & 4.0 & 4.0 \\
\hline GFT-1, g & Borehole stabilizer & Modified asphalt & 4.0 & 4.0 \\
\hline JNL-1, g & Thinner & Copolymer of propylene monomers & 0.5 & 0.5 \\
\hline $\mathrm{Na}_{2} \mathrm{SO}_{3}, \mathrm{~g}$ & Antioxidant & - & 0.7 & 0.7 \\
\hline SPC-220, g & Filtration control & Branched phenolic resins & 4.0 & 4.0 \\
\hline BOSST, $g$ & Thinner & Polymer & 1.0 & 1.0 \\
\hline SDR-1, g & Lubricant & Surfactant & 2.0 & 2.0 \\
\hline Barite* & Weighting agent & - & Used & - \\
\hline Barite-ilmenite* & Weighting agent & - & - & Used \\
\hline
\end{tabular}

Notes: * Barite and barite-ilmenite were used to elevate the fluid density to $2.2 \mathrm{~g} / \mathrm{cm}^{3}$. The mass ratio of barite to limonite was $1: 2$.

\subsection{Rheological measurements}

In this part, barite was used as weighting agent for fresh water-based drilling fluid and the mixture of barite-ilmenite (mass ratio is 1:2) as weighting agent for brine-based drilling fluid of a density of $2.2 \mathrm{~g} / \mathrm{cm}^{3}$. Before measurements, the fluids were hot rolled at $220{ }^{\circ} \mathrm{C}$ for $16 \mathrm{~h}$. For evaluating the rheological behavior, a rheometer (Fann 50SL, Fann Corp, USA) was used. Tests can be performed up to $260^{\circ} \mathrm{C}$ and 7 $\mathrm{MPa}$. The shear rate can be controlled from 0 to $1,022 \mathrm{~s}^{-1}$.

The density and rheological properties of the water-based drilling fluids are not sensitive to pressure change owing to the relatively low compressibility of water (Demirdal et al, 2007; Piber et al 2006). However, temperature has a significant effect on their rheological properties. In deep well drilling, the drilling fluid is circulated from the surface to the drilling zone in deep formations and subjected to high temperature and high pressure. Thus, the combined effect of pressure and temperature should be taken into consideration in following tests. The rheological parameters were evaluated at different temperatures and $5 \mathrm{MPa}$.

The experimental procedure for measuring rheological properties is as follows: 1) After placing the drilling fluid inside the rheometer, the sample was heated for $1 \mathrm{~h}$ up to the desired temperature. 2) $30 \mathrm{~min}$ of pre-shear at a shear rate of $1,022 \mathrm{~s}^{-1}$ was performed on each sample before rheological measurement in order to eliminate the effects of shearing, temperature, and pressure (Gusler et al, 2006; Saasen et al, 2008). 3) The pressure was adjusted to $5 \mathrm{MPa}$ and the shear stresses were measured at different shear rates (ranging from 0 to $\left.1,022 \mathrm{~s}^{-1}\right)$ and at different temperatures.

\subsection{Analysis of rheological properties of water-based drilling fluids}

\subsubsection{Rheological curves at different temperatures}

The rheological properties of two types of water-based drilling fluids were measured with the Fann rheometer at 5 $\mathrm{MPa}$, and the shear-stress versus shear-rate curves are shown in Fig. 1. The experimental results indicate that both highdensity drilling fluids behaved as plastic fluids at $50-220^{\circ} \mathrm{C}$. For the fresh water-based fluid, the shear stress decreased as the temperature increased at high shear rates. This is attributed to thermal dispersion and thermal dehydration of clay particles in the suspension. Though the plastic viscosity (PV) of the fluid increased with the degree of dispersion of solid particles, its structural viscosity decreased with increasing shear rate. The decrease in the structural viscosity was higher than the increase in the plastic viscosity. Therefore, the shear stress at high shear rates dropped rapidly with increasing temperature. However, the shear stress of brine-based fluid showed no significant trend as the temperature increased at high shear rates.

\subsubsection{The effect of temperature on the viscosity of drilling} fluids

The apparent viscosity (AV) and the plastic viscosity (PV) of water-based drilling fluids were measured at different temperatures $\left(50-220^{\circ} \mathrm{C}\right)$ and the results are shown in Fig. 2. 


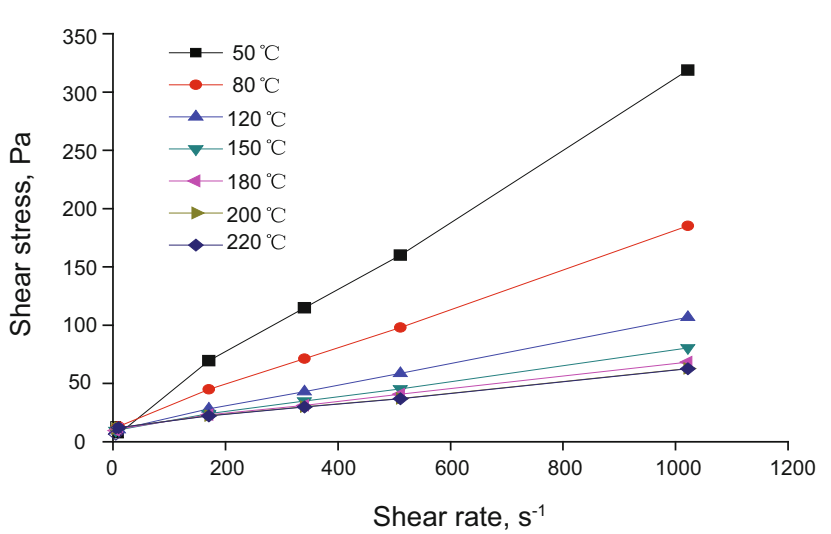

(a) Fresh water-based drilling fluid

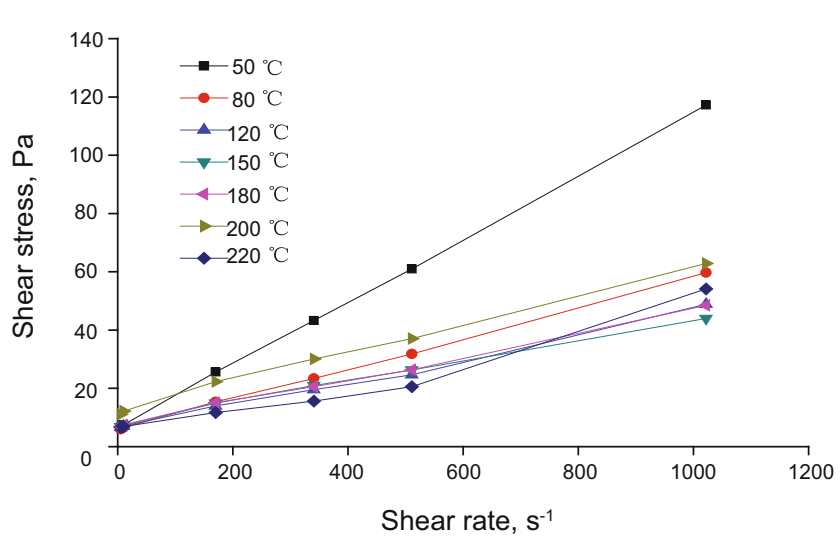

(b) Brine-based drilling fluid

Fig. 1 Rheological curves of drilling fluids at different temperatures

The results show that temperature heavily influenced the viscosity of the fresh water-based drilling fluid. The apparent viscosity and plastic viscosity of the fresh water-based fluid decreased with an increase in temperature. However, the brine-based fluid exhibited the lowest apparent viscosity and plastic viscosity at $150{ }^{\circ} \mathrm{C}$, after which both viscosity values began to increase. The values of apparent viscosity and plastic viscosity of two drilling fluids exceeded $20 \mathrm{mPa} \cdot \mathrm{s}$ and 15 $\mathrm{mPa} \cdot \mathrm{s}$ at $220^{\circ} \mathrm{C}$, respectively, indicating that the two drilling fluids had excellent cuttings carrying capacity under HTHP conditions.

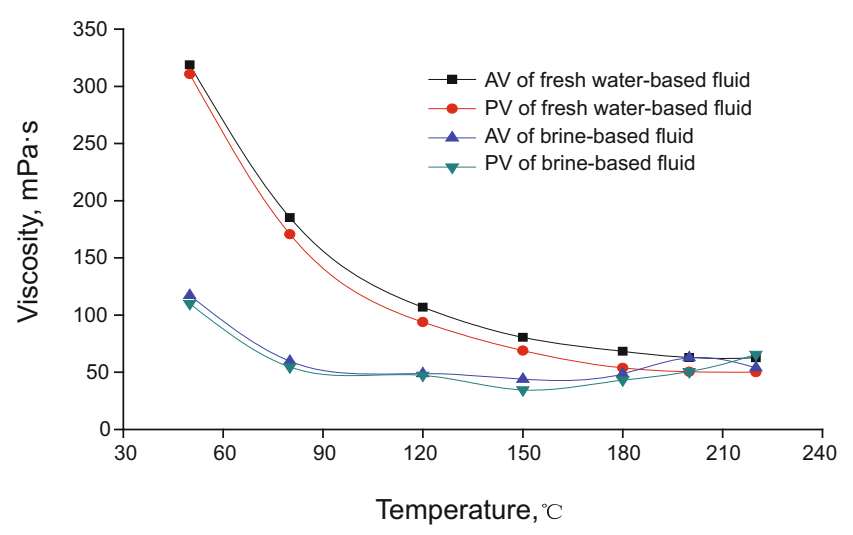

Fig. 2 Apparent viscosity and plastic viscosity of drilling fluids at different temperatures

\section{Factors influencing rheological properties of water-based fluids}

The rheological properties of the water-based fluid are influenced by a variety of factors. Focusing mainly on the fundamental components of the drilling fluid, systematic experiments were conducted to describe the influence of clay, weighting materials, the additive GHJ-1, fluid density, and aging temperature and time on the rheological parameters of the drilling fluids.

\subsection{Clay}

Clay content limit of the drilling fluid refers to the maximum and minimum clay contents (upper and lower limits) in the drilling fluid. When the clay content is between the upper and lower limits, the rheological parameters of the drilling fluid can remain stable at elevated temperatures. It is an inherent property of the drilling fluid. The clay content is required below $17.1 \mathrm{~kg} / \mathrm{m}^{3}$ when the density of the fluid exceeds $2.0 \mathrm{~g} / \mathrm{cm}^{3}$. When the actual clay content exceeds the upper limit, the fluid tends to thicken, gel or even solidify at high temperatures. If the actual clay content is below the lower limit, the fluid becomes thin at high temperatures and the viscosity decreases after exposure to high temperature. As for the two limits, the upper limit is more important than the lower one. The higher the upper limit and the larger the

Table 2 The compositions of brine-based drilling fluids

\begin{tabular}{|c|c|c|c|c|c|c|c|c|c|c|c|c|c|c|}
\hline \multirow[b]{2}{*}{$\begin{array}{c}\text { Drilling } \\
\text { fluid }\end{array}$} & \multicolumn{14}{|c|}{ Component } \\
\hline & $\begin{array}{c}\text { Water } \\
\mathrm{mL}\end{array}$ & $\begin{array}{c}\text { Sodium } \\
\text { bentonite } \\
\mathrm{g}\end{array}$ & $\begin{array}{c}\text { Sepiolite } \\
\mathrm{g}\end{array}$ & $\begin{array}{l}\text { Salt* } \\
\text { g }\end{array}$ & $\begin{array}{c}\text { GHJ-1 } \\
\text { g }\end{array}$ & $\begin{array}{c}\text { JZA-1 } \\
\text { g }\end{array}$ & $\begin{array}{l}\text { GJZA-1 } \\
\mathrm{g}\end{array}$ & $\begin{array}{c}\text { GFT-1 } \\
\text { g }\end{array}$ & $\begin{array}{c}\text { JNL-1 } \\
\mathrm{g}\end{array}$ & $\begin{array}{c}\mathrm{Na}_{2} \mathrm{SO}_{3} \\
\mathrm{~g}\end{array}$ & $\begin{array}{c}\mathrm{SPC}-220 \\
\mathrm{~g}\end{array}$ & $\begin{array}{c}\text { BOSST } \\
\mathrm{g}\end{array}$ & $\begin{array}{l}\text { SDR-1 } \\
\mathrm{g}\end{array}$ & Barite \\
\hline $1 \#$ & 100 & 1.0 & 3.0 & 15.0 & 1.5 & 3.0 & 4.0 & 4.0 & 0.5 & 0.7 & 4.0 & 1.0 & 2.0 & \\
\hline $2 \#$ & 100 & 1.0 & 2.0 & 15.0 & 1.5 & 3.0 & 4.0 & 4.0 & 0.5 & 0.7 & 4.0 & 1.0 & 2.0 & Used to increase \\
\hline $3 \#$ & 100 & 2.0 & 2.0 & 15.0 & 1.5 & 3.0 & 4.0 & 4.0 & 0.5 & 0.7 & 4.0 & 1.0 & 2.0 & to $1.5 \mathrm{~g} / \mathrm{cm}^{3}$ \\
\hline $4 \#$ & 100 & 4.0 & 0 & 15.0 & 1.5 & 3.0 & 4.0 & 4.0 & 0.5 & 0.7 & 4.0 & 1.0 & 2.0 & \\
\hline $5 \#$ & 100 & 0 & 2.0 & 15.0 & 1.5 & 3.0 & 4.0 & 4.0 & 0.5 & 0.7 & 4.0 & 1.0 & 2.0 & \\
\hline $6 \#$ & 100 & 1.0 & 1.0 & 15.0 & 1.5 & 3.0 & 4.0 & 4.0 & 0.5 & 0.7 & 4.0 & 1.0 & 2.0 & Used to increase \\
\hline $7 \#$ & 100 & 2.0 & 0 & 15.0 & 1.5 & 3.0 & 4.0 & 4.0 & 0.5 & 0.7 & 4.0 & 1.0 & 2.0 & to $2.2 \mathrm{~g} / \mathrm{cm}^{3}$ \\
\hline 8\# & 100 & 1.0 & 1.0 & 255.0 & 1.5 & 3.0 & 4.0 & 4.0 & 0.5 & 0.7 & 4.0 & 1.0 & 2.0 & \\
\hline
\end{tabular}

Notes: * In samples 1\#-7\#, $\mathrm{NaCl}$ was used, but in sample $8 \#$ HCOOK was used. 
differential value between the upper and the lower limits, the easier the rheological properties are to maintain. The formulations of brine-based drilling fluids are listed in Table 2.

\subsubsection{Brine-based fluids of a low-to-moderate density}

Samples 1\#-4\# (weighted to $1.5 \mathrm{~g} / \mathrm{cm}^{3}$ with barite) were used here. Table 3 lists the influence of mass ratio of sodium bentonite to sepiolite on the apparent viscosity, plastic viscosity and yield point of the drilling fluids before and after aging. The drilling fluids were aged at $180^{\circ} \mathrm{C}$ for $16 \mathrm{~h}$.

Table 3 Rheological properties of brine-based drilling fluids with a low-to-moderate density

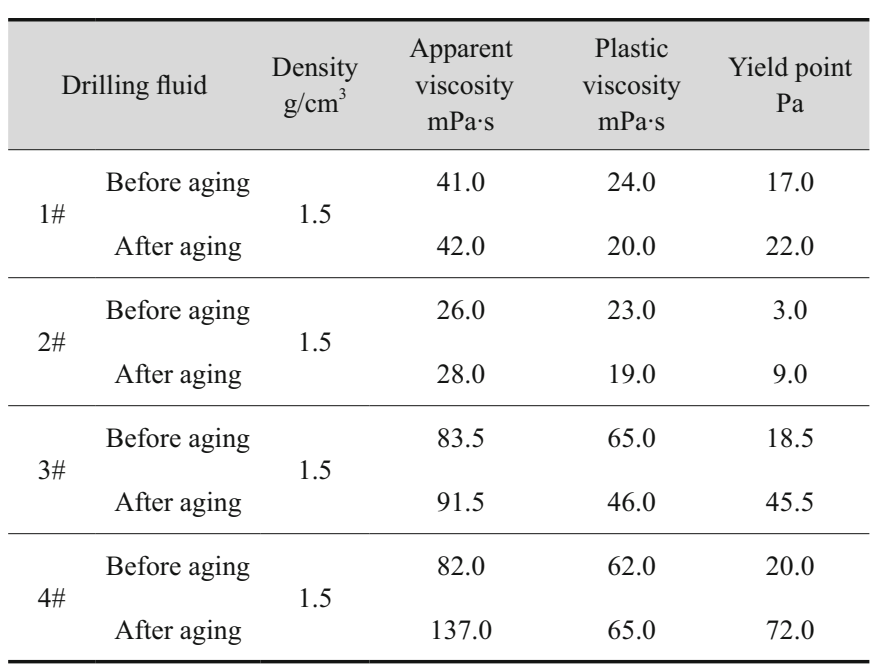

Notes: Aging at $180^{\circ} \mathrm{C}$ for $16 \mathrm{~h}$.

Table 3 shows that for brine-based fluids containing different contents of sodium bentonite and sepiolite (samples 1\#-3\#), the plastic viscosity decreased but the yield point increased after aging (hot rolling). As the relative content of sodium bentonite in fluids increased, the yield point of the fluids increased significantly. When the content of sodium bentonite in the fluids was below $2 \%(\mathrm{w} / \mathrm{v})$, the apparent viscosity changed slightly before and after aging. As the content of sodium bentonite exceeded $2 \%$, the apparent viscosity increased significantly after aging. This indicates that in the fluid with a high content of sodium bentonite, thermal treatment (hot rolling) promoted the formation of a gel structure of sodium bentonite. However, as the relative content of sepiolite increased, the viscosity and the yield point exhibited little variations before and after aging. This is mainly attributed to the excellent heat resistance of sepiolite, whose structure remained stable during aging. Thus, the key to maintaining the rheological properties of water-based drilling fluids is to control the clay content, especially the content of sodium bentonite. One effective technical measure is to use sepiolite, which is relatively stable to the changes of temperature and salinity, to substitute for sodium bentonite in a minimum concentration within clay capacity limits. The total content of clay in fluid $2 \#$ was $3 \%$, the viscosity and the yield point of the fluid remained unchanged after aging. For the fluid with a density below $1.5 \mathrm{~g} / \mathrm{cm}^{3}$, the clay content should be controlled below $3 \%$ and the ratio of sodium bentonite to sepiolite should be kept at 1:2.

\subsubsection{Fluids of a high density}

Samples 5\#-8\# (weighted to $2.2 \mathrm{~g} / \mathrm{cm}^{3}$ with barite) were used here. The rheological properties are shown in Table 4.

Table 4 Rheological properties of fluids of a high density

\begin{tabular}{|c|c|c|c|c|c|}
\hline \multicolumn{2}{|c|}{ Brine-based fluid } & $\begin{array}{l}\text { Density } \\
\mathrm{g} / \mathrm{cm} 3\end{array}$ & $\begin{array}{c}\text { Apparent } \\
\text { viscosity } \\
\mathrm{mPa} \cdot \mathrm{s}\end{array}$ & $\begin{array}{l}\text { Plastic } \\
\text { viscosity } \\
\mathrm{mPa} \cdot \mathrm{s}\end{array}$ & $\begin{array}{c}\text { Yield } \\
\text { point } \\
\mathrm{Pa}\end{array}$ \\
\hline \multirow{2}{*}{$5 \#$} & Before aging & \multirow{2}{*}{2.2} & 77.0 & 62.0 & 15.0 \\
\hline & After aging & & 58.0 & 28.0 & 30.0 \\
\hline \multirow{2}{*}{$6 \#$} & Before aging & \multirow{2}{*}{2.2} & 90.0 & 65.0 & 25.0 \\
\hline & After aging & & 60.5 & 45.0 & 15.5 \\
\hline \multirow{2}{*}{ 7\# } & Before aging & \multirow{2}{*}{2.2} & 103.0 & 76.0 & 27.0 \\
\hline & After aging & & 66.0 & 46.0 & 20.0 \\
\hline \multirow{2}{*}{$8 \#$} & Before aging & \multirow{2}{*}{2.2} & 47.5 & 42.0 & 5.5 \\
\hline & After aging & & 135.5 & 22.0 & 113.5 \\
\hline
\end{tabular}

Notes: Aging at $220^{\circ} \mathrm{C}$ for $16 \mathrm{~h}$.

Table 4 shows that the plastic viscosity of the fluids decreased after aging. As for brine-based fluids 5\#, 6\# and $7 \#$ (containing $15 \% \mathrm{NaCl}$ ), the yield point changed within the permitted range and the viscosity decreased after aging. Fluid 8\# (weighted with saturated potassium formate) became viscous after aging. The difference between samples $6 \#$ and $8 \#$ was that $15 \% \mathrm{NaCl}$ was introduced into sample $6 \#$ but saturated potassium formate was introduced into sample 8\#. Theoretical analysis indicates that the density of the saturated potassium formate solution is higher than that of the $15 \% \mathrm{NaCl}$ solution. The fluid $8 \#$ weighted with saturated potassium formate, contained a lower solid content than other fluids weighted by $\mathrm{NaCl}$ when they had the same density, besides the fluid possessed outstanding inhibitive properties which helped to control the rheological properties of highdensity fluids. However, experimental results show that when the fluid was weighted by barite, foam formed in the fluid and an unpleasant smell was emitted during aging. This indicates that some barite could dissolve in the saturated potassium formate solution under thermal conditions, and react with potassium formate to generate poisonous ( $\mathrm{HCOO})_{2} \mathrm{Ba}$, thus leading to loss of rheological properties. When the fluid was weighted with ilmenite instead of barite, the rheological properties of the fluid were still undesirable after aging. This is mainly because weighting materials would dissolve in the potassium formate solution at high temperatures. The fluid was contaminated by high valence ions (or cations), resulting in clay flocculation and then an increase in plastic viscosity. Therefore, a colloid stabilizer with high tolerance to highvalence cations should be employed to stabilize the colloidal suspension at high temperatures when designing high-density brine-based fluids. As for samples $5 \#-8 \#$, samples $6 \#$ and $7 \#$ were desirable. The viscosity and yield point of sample 6\# were a little lower than those of sample $7 \#$ both before and after aging. Moreover, the filtration loss of sample 6\# (15.6 $\mathrm{mL})$ was lower than that of sample $7 \#(19.2 \mathrm{~mL})$ at $220{ }^{\circ} \mathrm{C}$ 
and $3.5 \mathrm{MPa}$. Therefore, $2 \%$ clay content and a mass ratio of sodium bentonite to sepiolite of 1:1 are recommended to maintain the rheological properties of the fluid.

\subsection{Colloid stabilizer GHJ-1}

A colloid stabilizer GHJ-1 was prepared to enhance the thermal stability of the high-density fluid. GHJ-1 has high thermal stability, even at $240{ }^{\circ} \mathrm{C}$, and excellent resistance to salinity (saturated salt or calcium up to $12.5 \mathrm{~g} / \mathrm{L}$ ). Laboratory evaluations indicate that GHJ-1 possesses outstanding capacity to maintain the rheological properties of drilling fluids (colloidal suspension) at high temperatures and excellent properties to reduce fluid loss. Besides, because of its excellent compatibility with sulphonated additives commonly used in deep well drilling, GHJ-1 can greatly enhance the thermal stability of the drilling fluid with minimum costs.

The formulations of brine-based drilling fluid containing GHJ-1 are listed in Table 5. The influence of the colloid stabilizer GHJ-1 on the rheological properties of drilling fluids was examined and the experimental results are shown in Figs. 3 and 4. The samples were aged at $220^{\circ} \mathrm{C}$ for $16 \mathrm{~h}$.

Table 5 Composition of the brine-based drilling fluid

\begin{tabular}{|c|c|c|c|c|c|c|c|c|c|c|c|c|c|}
\hline $\begin{array}{l}\text { Water } \\
\mathrm{mL}\end{array}$ & $\begin{array}{c}\text { Sodium } \\
\text { bentonite } \\
\mathrm{g}\end{array}$ & $\begin{array}{c}\text { Sepiolite } \\
\mathrm{g}\end{array}$ & $\begin{array}{c}\mathrm{NaCl} \\
\mathrm{g}\end{array}$ & GHJ-1* & $\begin{array}{c}\text { JZA-1 } \\
\mathrm{g}\end{array}$ & $\begin{array}{c}\text { GJZA-1 } \\
\mathrm{g}\end{array}$ & $\begin{array}{c}\text { GFT-1 } \\
\text { g }\end{array}$ & $\begin{array}{c}\text { JNL-1 } \\
\mathrm{g}\end{array}$ & $\begin{array}{c}\mathrm{Na}_{2} \mathrm{SO}_{3} \\
\mathrm{~g}\end{array}$ & $\begin{array}{c}\text { SPC-220 } \\
\mathrm{g}\end{array}$ & $\begin{array}{c}\text { BOSST } \\
\mathrm{g}\end{array}$ & $\begin{array}{c}\text { SDR-1 } \\
\mathrm{g}\end{array}$ & $\begin{array}{c}\text { Barite- } \\
\text { ilmenite ** }\end{array}$ \\
\hline 100 & 1.0 & 1.0 & 15 & - & 3.0 & 4.0 & 4.0 & 0.5 & 0.7 & 4.0 & 1.0 & 2.0 & - \\
\hline
\end{tabular}

Notes: * GHJ-1 was added to the drilling fluid to the required GHJ-1 concentration (w/v), as shown in Figs. 3 and 4.

** Barite-ilmenite (mass ratio of 1:2) was used to increase the fluid density to $2.2 \mathrm{~g} / \mathrm{cm}^{3}$.

Fig. 3 indicates that the viscosity of the high-density fluids increased with the concentration of GHJ-1 before and after aging. GHJ-1, with a moderate-to-high molecular weight, formed a gel structure in the drilling fluid, thus thickening the fluid. Hence, special attention should be paid to the addition of GHJ-1 when optimizing the formulations. In experiments the concentration is required in the range of $1.0 \%$ to $2.0 \%$. It would be difficult to maintain the rheological properties of

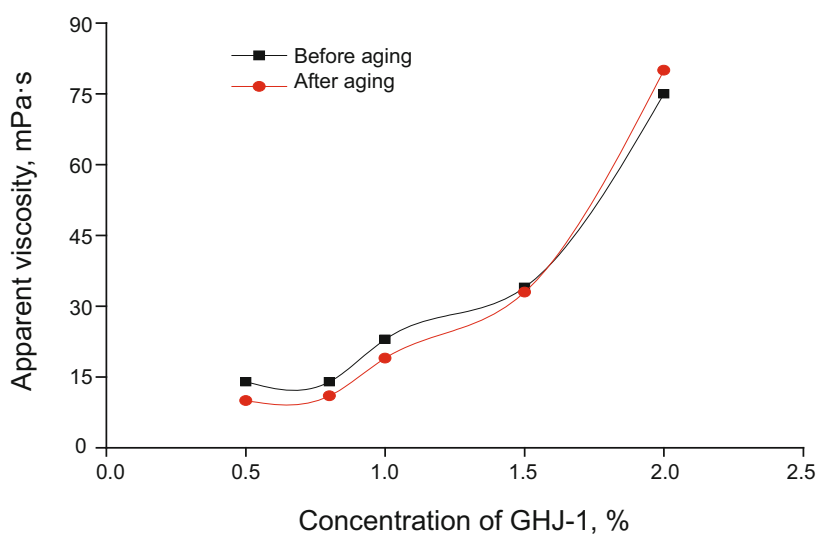

Fig. 3 The influence of the GHJ-1 concentration on the apparent viscosity of the high-density brine-based fluids

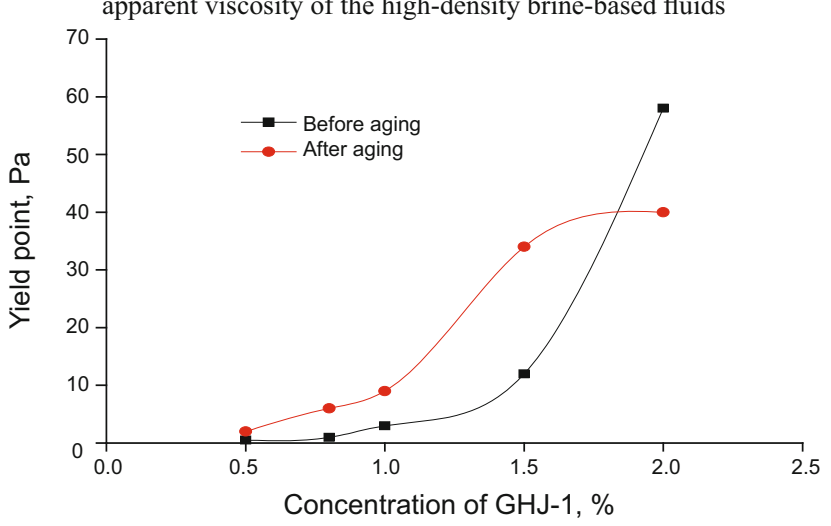

Fig. 4 The influence of the GHJ-1 concentration on the yield point of the high-density brine-based fluids the fluid when the addition of GHJ-1 exceeds $2 \%$.

The yield point reflects the strength of the gel structure formed by clay particles and high molecular polymer when the drilling fluid is in laminar flow. The gel structure formed by macromolecular GHJ-1 in the drilling fluid caused an increase in the yield point, but the viscosity and the yield point decreased to some extent after aging. During aging, hydrolysis of polymer chains takes place, but the degradation of free radicals in the molecular chain can be neglected. The drop of the yield point was not attributed to the decrease in the relative molecular weight of the polymer, but to the decrease in the node number and intensity in the gel structure. This is because the original group dehydrated into - $\mathrm{COOH}$ and the high density of negative charges altered the adsorption behavior on the clay particles. Fluid with a low addition of polymer thinned after aging. This was due to the hydrolysis of original group in the molecular chains. With more addition of polymer, the yield point of the drilling fluid increased again, as shown in Fig. 4.

\subsection{The density of drilling fluids}

High solids content is the obstacle encountered in maintaining rheological properties of water-based drilling fluids of high density. High degree of dispersion together with huge particle surface area greatly reduces free water in the fluid by adsorption and wettability, leading to the reduction in the cuttings capacity limits. Once contamination occurs, solid particles interplay and form a gel structure, causing an increase in the viscosity and shear stress. To maintain the rheological properties, the fluid should be discarded (Audibert et al, 1999; Shaughnessy et al, 2003). In this paper, the influence of density on rheological parameters of the drilling fluids was investigated by dynamic aging tests at $220{ }^{\circ} \mathrm{C}$. Here the formulation of brine-based fluid is listed in Table 1.

Figs. 5 and 6 show that as the density increased, both the apparent viscosity and the plastic viscosity increased before aging while the yield point first rose and then dropped. However, after aging the difference between apparent 
viscosity and plastic viscosity was not significant, the yield point first dropped then rose. Barite was used to elevate the density when the density of drilling fluids was below 1.8 $\mathrm{g} / \mathrm{cm}^{3}$, the relatively high solids content produced substantial friction. A mixture of barite and ilmenite (mass ratio 1:2) was used when the drilling fluid required a density above 1.8 $\mathrm{g} / \mathrm{cm}^{3}$, so the yield point of the fluid of a density of 1.8 $\mathrm{g} / \mathrm{cm}^{3}$ was lower than that of the fluid of a density of 1.5 $\mathrm{g} / \mathrm{cm}^{3}$. However, as the density continued to rise, the yield point increased gradually. When mixing the high density drilling fluid at a high stirring rate, some bubbles were produced and the free water was greatly reduced due to the addition of a large amount of weighting materials (710 $\mathrm{g}$ barite was added to attain $2.2 \mathrm{~g} / \mathrm{cm}^{3}$ for $350 \mathrm{~mL}$ drilling fluid). What is more, the addition of GHJ-1 could make the fluid thicken. So before aging the viscosity increased with increasing fluid density. The decreases in viscosity and yield point after aging was mainly attributed to some thermal degradation of the additive and accordingly a decrease in the molecular weight.

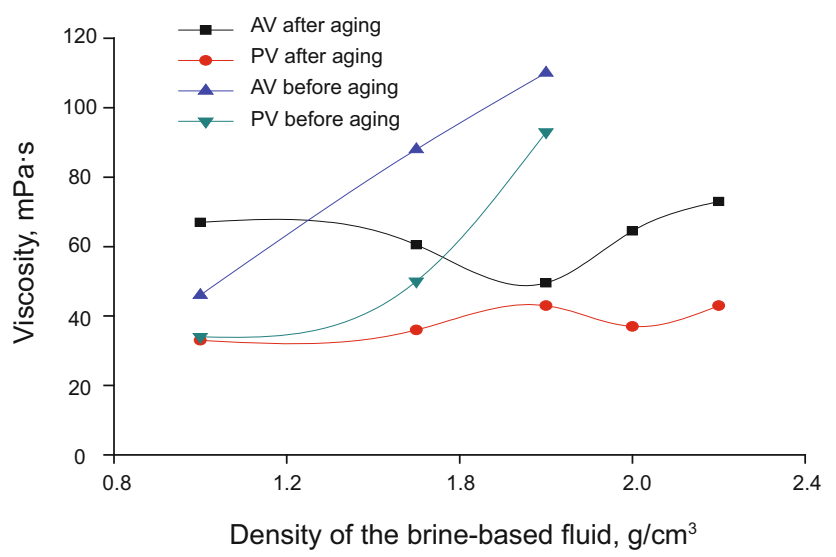

Fig. 5 The influence of density on the apparent viscosity and plastic viscosity of the brine-based fluid

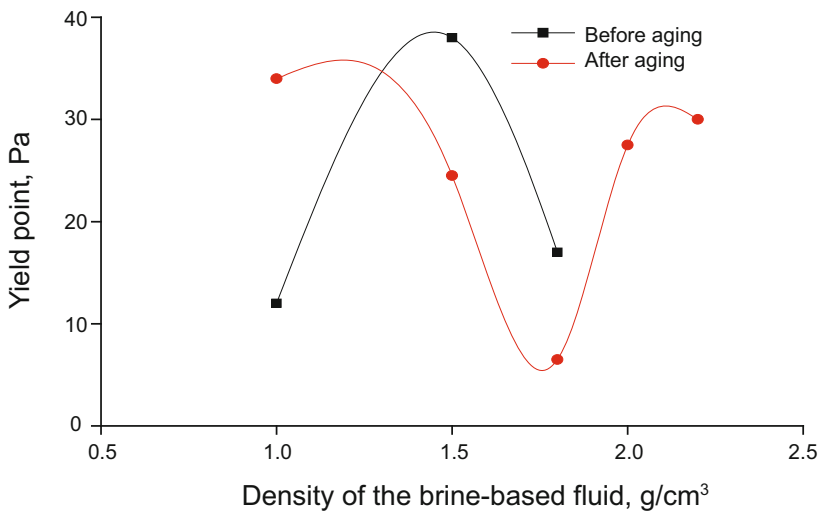

Fig. 6 The influence of density on the yield point of the brine-based fluid

\subsection{Aging temperature}

The behavior of drilling fluids will change with increasing aging temperature. Temperature aggravates the degradation of additives, desorption of additives on clay surfaces and the dehydration of hydrophilic groups in additives. Consequently, elevated temperature reduces the effectiveness of fluid additives that protect the clay particles. Temperature exerts a complex influence on rheological properties of drilling fluids and the effect of temperature on viscosity can be classified into three categories. 1) High temperature thinning. The viscosity decreases with increasing temperature, causing a reduction in carrying capacity and suspending ability of cuttings then barite sags when breaking circulation and tripping or settles in the fluid ditch. 2) High temperature thickening. The fluid experiences an increase in viscosity and yield point after aging at high temperatures thus losing its fluidity (gelation after a high temperature treatment). 3) High temperature solidification. The fluid completely lost fluidity (Bland et al, 2006). The formulations of fresh-water and brine-based drilling fluid are listed in Table 1. Mixture of barite-ilmenite (mass ratio of 1:2) was employed as weighting agent for $2.2 \mathrm{~g} / \mathrm{cm}^{3}$. Exact experimental results are presented in Table 6 .

Table 6 Rheological properties of fresh water-based and brine-based fluids at different temperatures

\begin{tabular}{ccccc}
\hline Fluid sample & $\begin{array}{c}\text { Aging temperature } \\
{ }^{\circ} \mathrm{C}\end{array}$ & $\begin{array}{c}\text { Apparent } \\
\text { viscosity } \\
\mathrm{mPa} \cdot \mathrm{s}\end{array}$ & $\begin{array}{c}\text { Plastic } \\
\text { viscosity } \\
\mathrm{mPa} \cdot \mathrm{s}\end{array}$ & $\begin{array}{c}\text { Yield point } \\
\mathrm{Pa}\end{array}$ \\
\hline \multirow{6}{*}{ Fresh-water based } & 180 & 88.0 & 67.0 & 21.0 \\
& 200 & 35.0 & 28.0 & 7.0 \\
& 220 & 37.0 & 27.0 & 10.0 \\
& 240 & 70.0 & 33.0 & 37.0 \\
\hline \multirow{3}{*}{ Brine-based } & 20 & 47.0 & 31.0 & 18.0 \\
& 180 & 41.0 & 25.0 & 16.0 \\
& 200 & 69.0 & 42.0 & 27.0 \\
& 220 & 67.0 & 42.5 & 24.5 \\
\hline
\end{tabular}

It can be seen from Table 6, when the aging temperature was below $220^{\circ} \mathrm{C}$, for the brine-based fluids the viscosity and the yield point changed slightly with temperature, indicating excellent rheological properties. While for the fresh waterbased fluid the viscosity and the yield point dropped after aging. When the aging temperature was $240{ }^{\circ} \mathrm{C}$, the viscosity and yield point of the brine fluid increased sharply, resulting in loss of rheological properties and high filtration loss at HTHP conditions (filtration loss was $72 \mathrm{~mL}$ at $240{ }^{\circ} \mathrm{C}$ and 3.5 $\mathrm{MPa}$ ). The yield point of the fresh water-based fluid increased slightly after aging. This is mainly because the additives degraded at high temperatures and their ability to protect clay particles reduced, and then the hydration layer surrounding clay particles became thin, thus resulting in aggregation of clay particles. Consequently, the viscosity and the yield point exhibited a slight increasing trend.

\subsection{Aging time}

The brine- and fresh water-based fluid with a density of $2.2 \mathrm{~g} / \mathrm{cm}^{3}$ were continuously rolled at $220{ }^{\circ} \mathrm{C}$ for $72 \mathrm{~h}$. Performances were evaluated after aging for 16, 24, 48, and $72 \mathrm{~h}$, respectively, and listed in Table 7. The apparent viscosity and the yield point of drilling fluids increased 
with aging time, but the plastic viscosity first rose and then dropped.

Table 7 The influence of aging time on the rheological properties of drilling fluids

\begin{tabular}{ccccc}
\hline Fluid sample & $\begin{array}{c}\text { Aging time } \\
\mathrm{h}\end{array}$ & $\begin{array}{c}\text { Apparent } \\
\text { viscosity } \\
\mathrm{mPa} \cdot \mathrm{s}\end{array}$ & $\begin{array}{c}\text { Plastic } \\
\text { viscosity } \\
\mathrm{mPa} \cdot \mathrm{s}\end{array}$ & $\begin{array}{c}\text { Yield point } \\
\mathrm{Pa}\end{array}$ \\
\hline \multirow{2}{*}{ Fresh water-based } & 16 & 57.5 & 47 & 10.5 \\
& 48 & 115.0 & 71 & 44 \\
& 72 & 135.0 & 62 & 73 \\
\hline \multirow{3}{*}{ Brine-based } & 16 & 73.0 & 43 & 90 \\
& 32 & 119.0 & 69 & 50 \\
& 48 & 122.5 & 72 & 50.5 \\
& 72 & 124.0 & 54 & 70 \\
\hline
\end{tabular}

\section{Rheological models for high-density drilling fluids at HTHP conditions}

Four widely-used rheological models, the Bingham, power law, Casson and H-B models, were used to estimate the rheological properties of drilling fluids (Bailey and Weir, 1998). This paper aimed at experimental data above 150 ${ }^{\circ} \mathrm{C}$ and fitted them to the above rheological model using linear regression. The rheological fitting equations and their predictive qualities are presented in Tables 8 and 9. For highdensity fresh water- and brine-based drilling fluids, the $\mathrm{H}-\mathrm{B}$ model provided the best fits at $150-220{ }^{\circ} \mathrm{C}$ among the four rheological models.

Table 8 Fitting equations and corresponding correlation coefficients of four models for high-density fresh water-based drilling fluids

\begin{tabular}{|c|c|c|c|}
\hline Model & $\begin{array}{c}\text { Temperature } \\
{ }^{\circ} \mathrm{C}\end{array}$ & Rheological equation & $\begin{array}{c}\text { Correlation } \\
\text { coefficient } \\
R\end{array}$ \\
\hline \multirow{4}{*}{ Bingham } & 150 & $\tau=10.52+0.068 \gamma$ & 0.9990 \\
\hline & 180 & $\tau=11.25+0.056 \gamma$ & 0.9977 \\
\hline & 200 & $\tau=12.13+0.049 \gamma$ & 0.9964 \\
\hline & 220 & $\tau=12.12+0.0496 \gamma$ & 0.9987 \\
\hline \multirow{4}{*}{ Power law } & 150 & $\tau=4.58 \gamma^{0.373}$ & 0.9730 \\
\hline & 180 & $\tau=5.03 \gamma^{0.338}$ & 0.9742 \\
\hline & 200 & $\tau=6.17 \gamma^{0.294}$ & 0.9630 \\
\hline & 220 & $\tau=6.23 \gamma^{0.29}$ & 0.9609 \\
\hline \multirow{4}{*}{ H-B } & 150 & $\tau=9.0+0.172 \gamma^{0.86}$ & 0.9999 \\
\hline & 180 & $\tau=8.0+0.616 \gamma^{0.64}$ & 0.9975 \\
\hline & 200 & $\tau=10.0+0.38 \gamma^{0.69}$ & 0.9974 \\
\hline & 220 & $\tau=10.6+0.218 \gamma^{0.778}$ & 0.9987 \\
\hline \multirow{4}{*}{ Casson } & 150 & $\sqrt{\tau}=2.522+0.192 \sqrt{\gamma}$ & 0.9965 \\
\hline & 180 & $\sqrt{\tau}=2.672+0.538 \sqrt{\gamma}$ & 0.9972 \\
\hline & 200 & $\sqrt{\tau}=2.896+0.148 \sqrt{\gamma}$ & 0.9944 \\
\hline & 220 & $\sqrt{\tau}=2.9+0.148 \sqrt{\gamma}$ & 0.9940 \\
\hline
\end{tabular}

Table 9 Fitting equations and corresponding correlation coefficients of four models for high-density brine-based drilling fluids

\begin{tabular}{|c|c|c|c|}
\hline Model & $\begin{array}{c}\text { Temperature } \\
{ }^{\circ} \mathrm{C}\end{array}$ & Rheological equation & $\begin{array}{c}\text { Correlation coefficient } \\
R\end{array}$ \\
\hline \multirow{4}{*}{ Bingham } & 150 & $\tau=7.632+0.036 \gamma$ & 0.9978 \\
\hline & 180 & $\tau=7.06+0.04 \gamma$ & 0.9986 \\
\hline & 200 & $\tau=3.49+0.049 \gamma$ & 0.9984 \\
\hline & 220 & $\tau=3.75+0.045 \gamma$ & 0.9737 \\
\hline \multirow{4}{*}{ Power law } & 150 & $\tau=3.51 \gamma^{0.326}$ & 0.9707 \\
\hline & 180 & $\tau=3.52 \gamma^{0.330}$ & 0.9611 \\
\hline & 200 & $\tau=6.17 \gamma^{0.294}$ & 0.9630 \\
\hline & 220 & $\tau=3.23 \gamma^{0.32}$ & 0.8916 \\
\hline \multirow{4}{*}{ H-B } & 150 & $\tau=6.27+0.154 \gamma^{0.78}$ & 0.9995 \\
\hline & 180 & $\tau=6.36+0.162 \gamma^{0.78}$ & 0.9981 \\
\hline & 200 & $\tau=10.0+0.38 \gamma^{0.69}$ & 0.9974 \\
\hline & 220 & $\tau=6.45+0.034 \gamma^{0.996}$ & 0.9938 \\
\hline \multirow{4}{*}{ Casson } & 150 & $\sqrt{\tau}=2.22+0.422 \sqrt{\gamma}$ & 0.9973 \\
\hline & 180 & $\sqrt{\tau}=2.175+0.141 \sqrt{\gamma}$ & 0.9912 \\
\hline & 200 & $\sqrt{\tau}=2.896+0.148 \sqrt{\gamma}$ & 0.9944 \\
\hline & 220 & $\sqrt{\tau}=1.857+0.145 \sqrt{\gamma}$ & 0.9416 \\
\hline
\end{tabular}

\section{Predictive model for the apparent viscosity of drilling fluids under HTHP conditions}

Field operations necessitate the ability to quickly calculate the apparent viscosity of drilling fluids under specific downhole conditions from the apparent viscosity measured at the wellhead. The down-hole viscosity as a function of the apparent viscosity measured at the wellhead needs to be plotted. As the drilling fluids are circulated to the bottom of the borehole at deep formations they are subjected to high temperature and high pressure. However, pressure and pressure variation have only a slight effect on rheological properties of fluids. Emphasis is placed on the influence of temperature on the rheological properties of drilling fluids. Parameters of the drilling fluid at a given pressure with temperature changes were tested. Taking both temperature and pressure into consideration, the viscosity as a function of temperature and pressure can be rewritten into (Zhao et al, 2007):

$$
\eta_{T, p}=\eta_{0} \exp (a T+b p)
$$

where $\eta$ is the apparent viscosity, $\mathrm{mPa} \cdot \mathrm{s} ; p$ is the fixed pressure, MPa.

Regression fitting was conducted by substituting into Eq. (1) the apparent viscosities of the high-density drilling fluid measured at different temperatures (at a shear rate of 1,022 $\left.\mathrm{s}^{-1}\right)$. The regression model and correlation coefficient $(R)$ were obtained and listed in Table 10. The returned drilling fluid at the wellhead possesses high temperature due to the bottomhole conditions in deep wells. The apparent viscosity of the fluid measured at $80^{\circ} \mathrm{C}$ can be seen as the viscosity of the returned drilling fluid at the wellhead. 
Table 10 The regression model and the data used

\begin{tabular}{cccccc}
\hline \multirow{2}{*}{ Regression model } & Temperature & \multicolumn{2}{c}{$\begin{array}{c}\text { Apparent viscosity } \\
\mathrm{mPa} \cdot \mathrm{s}\end{array}$} & $\begin{array}{c}\text { Correlation } \\
\text { coefficient } R\end{array}$ & $\begin{array}{c}\text { Relative } \\
\text { error } \\
E_{\mathrm{r}}, \%\end{array}$ \\
\cline { 3 - 4 } & 80 & 157.31 & 149.80 & 5.01 \\
$\eta_{T, p}=149.8 \operatorname{Cexp}(-0.011 T+0.78664 p)$ & 120 & 101.31 & 90.41 & & 12.06 \\
& 150 & 72.84 & 70.06 & 0.9905 & 3.97 \\
& 180 & 52.36 & 56.36 & & -7.09 \\
& 200 & 42.02 & 41.20 & & 2.00 \\
& 220 & 33.72 & 37.38 & & -9.77 \\
\hline
\end{tabular}

Notes: $E_{\mathrm{r}}=\frac{\eta_{\text {calculated }}-\eta_{\text {measured }}}{\eta_{\text {mesured }}} \times 100 \%, p$ is the test pressure of $5 \mathrm{MPa}$.

Table 10 indicates that the correlation coefficients of the regression model were high $(R>0.99)$. The apparent viscosity estimated with the model had a maximum error of $12.06 \%$, showing good agreement with the measured value and completely satisfying the requirement for apparent viscosity accuracy. Thus the apparent viscosity of the drilling fluid is an exponential function of temperature. Utilizing this model in conjunction with surface apparent viscosity, geothermal gradient and pressure gradient, the apparent viscosity of the drilling fluid at a specific depth can be estimated, which can be applied on site.

\section{Conclusions}

1) The effective measures to control the rheological properties of high-density drilling fluids are to reduce the total clay content and employ sepiolite. In order to better maintain the fluid rheological properties, the total clay content should be kept at 3\% and the mass ratio of bentonite to sepiolite $1: 2$ in the brine-based drilling fluid of a low-and-moderate density $\left(\rho=1.5 \mathrm{~g} / \mathrm{cm}^{3}\right)$; the total clay content should be less than $2 \%$ and the mass ratio of bentonite to sepiolite $1: 1$ in the brine-based drilling fluid of a high density $\left(\rho=2.2 \mathrm{~g} / \mathrm{cm}^{3}\right)$.

2) GHJ-1 could remarkably enhance the thermal stability of the drilling fluid, but the concentration of GHJ-1 could affect the rheological properties of the drilling fluid. The evaluation results indicate that as the concentration of GHJ-1 increased, the viscosity rose. Its concentration was desirable in the range of $1.0 \%$ to $1.5 \%$. It would be difficult to maintain the rheological properties of the fluid when the concentration of GHJ-1 exceeded $2 \%$.

3) The reason why density affects the rheological properties of the water-based drilling fluid is that the weighting materials cause the solid content to increase. There are two ways to reduce the solid content in the highdensity drilling fluid. First, a soluble salt is used to increase the density of the base fluid. Second, high-density weighting materials can be used to reduce the solid content. Aging temperature and aging time exerted a slight influence on the viscosity of the water-based drilling fluid. In field application, the appropriate content of additives is essential to maintain the rheological parameters within a reasonable range.
4) Temperature heavily influenced the viscosity of the fresh water-based drilling fluid. The apparent viscosity and plastic viscosity of the fresh water based fluid decreased with an increase in temperature. The brine-based fluid had the lowest apparent viscosity and plastic viscosity at $150{ }^{\circ} \mathrm{C}$.

5) With the linear regression method, for high-density drilling fluids, the H-B model fitted the HTHP rheological parameters best. The established mathematical model can accurately describe the viscosity as a function of temperature and pressure.

\section{Acknowledgements}

The efforts of Professor Yan Jienian in the China University of Petroleum (Beijing) are especially appreciated.

\section{References}

Attia M, Elsorafy W and Stefano D A. New engineered approach to replace oil-based drilling fluids with high performance water-based drilling fluids in Mediterranean Sea. Paper SPE 127826 presented at North Africa Technical Conference and Exhibition, 14-17 February 2010, Cairo, Egypt

Audibert A, Rousseau L and Kieffer J. Novel high-pressure high temperature fluid loss reducer for water-based Formulation. Paper SPE 50724 presented at SPE International Symposium on Oilfield Chemistry, 16-19 February 1999, Houston, Texas

Bailey W J and Weir I S. Investigation of methods for direct rheological model parameter estimation. Journal of Petroleum Science and Engineering. 1998. 21: 1-13

Bland R, Mullen G, Gonzalez Y, et al. HPHT drilling fluid challenges. Paper SPE 103731 at IADC/SPE Asia Pacific Drilling Technology Conference and Exhibition, 13-15 November 2006, Bangkok, Thailand

Demirdal B, Miska S, Takach N, et al. Drilling fluids rheological volumetric characterization under downhole conditions. Paper 108111 presented at Latin American and Caribbean Petroleum Engineering Conference, 15-18 April, 2007, Buenos Aires, Argentina

Ezell R and Harrison J D. Design of improved high-density, thermally stable drill in fluid for HT/HP applications. Paper SPE 115537 presented at SPE Annual Technical Conference and Exhibition, 2124 September 2008, Denver, Colorado

Gusler W, Pless M, Maxey J, et al. A new extreme HP/HT viscometer for new drilling fluid challenges. Paper SPE 99009 presented at IADC/ 
SPE Drilling Conference, 21-23 February 2006, Miami, Florida

Kar Y, Al- Moajil A M, Nasr-El-Din H A, et al. Environmentally friendly dispersants for $\mathrm{HP} / \mathrm{HT}$ aqueous drilling fluids containing $\mathrm{Mn}_{3} \mathrm{O}_{4}$, contaminated with cement, rock salt and clay. Paper SPE 141957 presented at Middle East Oil and Gas Show and Conference, 25-28 September 2011, Banama, Bahrain

Piber M, Prohaska M, Hublik G, et al. Time-dependent behavior of drilling fluids under cyclic temperature and pressure loads. Paper SPE 102127 presented at SPE Annual Technical Conference and Exhibition, 24-27 September 2006, San Antonio, Texas

Pu X L, Huang L J, Luo X S, et al. Principle of rheology and filtration control of high-density water-based drilling fluid for deep wells. Natural Gas Industry. 2001. 21(6): 48-51 (in Chinese)

Saasen A, Omland H T , Ekrene S, et al. Automatic measurement of drilling fluid and drill cuttings properties. Paper SPE 112687 presented at IADC/SPE Drilling Conference, 4-6 March 2008, Orlando, Florida

Samaei M S and Tahmasbi K. The possibility of replacing oil-based mud with the environmentally acceptable water-based glycol drilling mud for the Iranian Fields. Paper SPE 106419 presented at E\&P
Environmental and Safety Conference, 5-7 March 2007, Galveston, Texas

Shaughnessy M J, Romo A L and Soza L R. Problems of ultra-deep hightemperature, high-pressure drilling. Paper SPE 84555 at SPE Annual Technical Conference and Exhibition, 5-8 October 2003, Denver, Colorado

Tehrani M A, Popplestone A, Guarneri A, et al. Water-based drilling fluid for HT/HP applications. Paper SPE 105485 presented at International Symposium on Oilfield Chemistry, 28 February-2 March, 2007, Houston, Texas

Wang F H and Wu M Q. Preparation and application of organic positive gel-polymer drilling fluid. Acta Petrolei Sinica. 2004. 25(5): 93-98 (in Chinese)

Wang F H, Wang L and Zhang Y H. Mechanisms of rheology adjustment and control of water base drilling fluid for deep wells. Fault-block Oil \& Gas Field. 2007. 14(5): 61-63 (in Chinese)

Zhao S Y, Yan J N, Ding T W, et al. Study of rheological properties of high temperature high density water based drilling fluid. Natural Gas Industry. 2007. 27(5): 78-80 (in Chinese)

(Edited by Sun Yanhua) 